\title{
Effect of Film Thickness and Physical Aging on "Intrinsic" Gas Permeation Properties of Microporous Ethanoanthracene-Based Polyimides
}

\author{
Xiaohua Ma and Ingo Pinnau* \\ King Abdullah University of Science and Technology (KAUST), \\ Functional Polymer Membranes Group, Advanced Membranes and Porous Materials Center, \\ Division of Physical Sciences and Engineering, Thuwal 23955, KSA.
}

*E-mail: Ingo.Pinnau @kaust.edu.sa 


\section{ABSTRACT}

Two ethanoanthracene-based dianhydrides, 9,10-dimethylethanoanthracene-2,3,6,7tetracarboxylic anhydride (EA-DA) and its more flexible dibenzodioxane-containing derivative (EAD-DA), were synthesized from the same starting material, 9,10-dimethyl-ethanoanthracene2,3,6,7-tetraol, and used for the preparation of bicyclic intrinsically microporous polyimides (PIM-PIs) by one-pot polycondensation reaction with 3,3'-dimethylnaphthidine (DMN). The resulting organosoluble polyimides, EA-DMN and EAD-DMN, were thermally stable up to $300{ }^{\circ} \mathrm{C}$ and had good mechanical properties with tensile strength of 55 and $63 \mathrm{MPa}$ and elongation at break of 15 and $30 \%$, respectively. EA-DMN and EAD-DMN polyimides displayed Brunauer-Emmett-Teller (BET) surface areas of 720 and $800 \mathrm{~m}^{2} \mathrm{~g}^{-1}$, respectively. Fresh films showed promising gas separation performance with very high gas permeabilities and moderate gas-pair selectivities, which were both strongly dependent on film thickness. The results obtained in this study shed more light on the relative importance of film thickness and physical aging on faster attainment of the "intrinsic" gas transport properties of high free volume PIM-PIs. 


\section{INTRODUCTION}

Polymers of intrinsic microporosity (PIMs) are a burgeoning class of advanced membrane materials for nanofiltration, pervaporation and gas separations. ${ }^{1-6}$ PIMs are characterized by high Brunauer-Emmett-Teller (BET) surface area up to $\sim 1,000 \mathrm{~m}^{2} \mathrm{~g}^{-1}$ with micropores $<20 \AA$, as determined by gas sorption measurements. PIMs typically display high gas permeability with moderate gas-pair selectivity; furthermore, some recently reported optimized ladder PIMs with fine-tuned microstructure containing a large fraction of ultra-micropores $(<7 \AA)$ displayed enhanced selectivity and defined the 2015 permeability/selectivity upper bounds for important industrial separations, specifically $\mathrm{O}_{2} / \mathrm{N}_{2}, \mathrm{H}_{2} / \mathrm{N}_{2}$ and $\mathrm{H}_{2} / \mathrm{CH}_{4} \cdot{ }^{7-11}$ However, one impediment for the commercial use of PIMs for membrane-based gas separations is their inherent nonequilibrium glassy state which leads to strongly time-dependent permeability and selectivity values due to physical aging of the polymer. During the aging process the rigid glassy polymer matrix slowly densifies due to chain relaxation towards its equilibrium physical state, which leads to reduction in the excess free volume initially frozen in the pristine polymer film. ${ }^{12}$ Consequently, gas permeability typically decreases and gas-pair selectivity increases with aging time. ${ }^{13}$ The aging process has significant effects on the true "intrinsic" gas transport properties of high-free-volume PIMs. Recent studies demonstrated that the aging rate that determines the permeability decline depends strongly on the polymer type and film thickness. ${ }^{14-17}$ In general, high-free-volume PIMs exhibit a more significant drop in gas permeability at a faster rate than conventional low-free-volume glassy polymers used for membrane-based gas separations, such as polysulfone, poly(phenylene oxide) etc..$^{15,18-20}$ This result appears counter-intuitive as ladder PIMs or semi-ladder polyimides of intrinsic microporosity (PIM-PIs) are considered to be highly rigid materials. The term "rigidity" has been used to relate the high gas permeabilities of PIMs 
and PIM-PIs to structural chain stiffness and steric hindrance induced by sites of contortion in the main chain. ${ }^{6,21,22}$ The gas permeation properties of PIMs and PIM-PIs are usually reported for freshly prepared, "unaged" film samples which are then compared to previously published data of other polymers, typically in a permeability/selectivity Robeson upper bound plot to assess their performance relative to state-of-the-art polymers. ${ }^{23}$ This methodology provides transientstate permeability and selectivity data which are only a first indication of the performance of a newly developed glassy polymer membrane material for gas separations. However, in order to properly design a membrane process for any specific application, reliable gas permeability and selectivity data are required which essentially represent the "equilibrium" physical state of the polymer.

Previous studies demonstrated clearly that the attainment of equilibrium permeability and selectivity values can reach several years when highly rigid glassy PIMs or PIM-PIs films with thicknesses of $\sim>100 \mu \mathrm{m}$ are used. ${ }^{6,11,18,20}$ For example, this trend has been demonstrated for a $102 \mu$ m-thick PIM-1 film aged for 1380 days that showed $\sim 70 \%$ decrease in $\mathrm{O}_{2}$ permeability from 1076 to 317 Barrer $\left(1\right.$ Barrer $\left.=10^{-10} \mathrm{~cm}^{3}(\mathrm{STP}) \mathrm{cm} \mathrm{cm}^{-2} \mathrm{~s}^{-1} \mathrm{cmHg}^{-1}\right)$ with a concurrent increase in $\mathrm{O}_{2} / \mathrm{N}_{2}$ selectivity from $\sim 3.5$ to $5.0 .{ }^{20} \mathrm{~A}$ recent study by Tiwari et al. demonstrated that significantly accelerated aging can be achieved by using thin $(\sim 30 \mu \mathrm{m}$ made by solution casting $)$ and ultrathin $(\sim 1 \mu \mathrm{m}$ made by spin-coating $)$ PIM-1 films. ${ }^{18}$ For the $1-\mu \mathrm{m}$-thick film an $\mathrm{O}_{2} / \mathrm{N}_{2}$ selectivity of $\sim 5$ was obtained after only $\sim 1-2$ days of aging which remained constant over extended aging periods. Clearly, it is favourable to use ultrathin films to quickly approach the equilibrium state of glassy polymers to determine their true intrinsic gas permeation properties. However, this approach is often limited by the difficulty in preparing ultrathin $(<1 \mu \mathrm{m})$, defectfree and mechanically strong freestanding polymer films. 
In this work, the gas permeabilities and gas-pair selectivities of two related ethanoanthracene-based PIM-PIs were investigated with respect to their intra-chain rigidity and film thickness as function of aging time. It was demonstrated that "intrinsic" gas permeation properties of these PIM-PIs can be approached over a relatively short time scale by using isotropic films with thickness of $\sim 10-30 \mu \mathrm{m}$.

\section{EXPERIMENTAL}
Materials.
Trifluoromethanesulfonic
anhydride
$\left(\mathrm{Tf}_{2} \mathrm{O}\right)$

tris(dibenzylideneacetone)dipalladium $\left(\mathrm{Pd}_{2}(\mathrm{dba})_{3}\right), 1,1^{\prime}$-bis(diphenylphosphino)ferrocene (DPPF), zinc cyanide $\left(\mathrm{Zn}(\mathrm{CN})_{2}\right)$, 4,5-dichlorophthalonitrile, potassium carbonate, potassium hydroxide, m-cresol, tetrahydrofuran, acetic anhydride, methanol, ethanol, triethylamine, hydrochloride acid, dichloromethane, petroleum ether, $N, N$-dimethylformamide and isoquinoline were obtained from Sigma-Aldrich and used as received. 3,3'-dimethylnaphthidine (DMN) was obtained from TCI and used directly. 9,10-Dimethyl-ethanoanthracene-2,3,6,7-tetraol was synthesized as previously reported. $^{24}$

Characterization and Methods. ${ }^{1} \mathrm{H}$ NMR and ${ }^{13} \mathrm{C}$ NMR spectra of the monomer and polymers were recorded with a Bruker AVANCE-III spectrometer at a frequency of 400 or 500 $\mathrm{MHz}$ in deuterated chloroform or deuterated dimethylsulfone with tetramethylsilane as an internal standard; the chemical shifts were recorded in ppm. Molecular weight $\left(\mathrm{M}_{\mathrm{n}}\right)$ and molecular weight distribution (PDI) of the polymers were obtained by gel permeation chromatography (GPC, Malvern HT-350) using chloroform as solvent and polystyrene as external standard. High-resolution mass spectroscopy (HRMS) of the monomers was conducted on a Thermo LC/MS system with LTQ Orbitrap Velos detectors. Thermal gravimetric analysis 
(TGA) was carried out with a TGA Q5000. Fourier transform infrared spectroscopy (FT-IR) analyses of the polyimides were aquired using a Varian 670-IR spectrometer. Elemental analysis was carried out using a Perkin-Elmer $2400 \mathrm{CHN}$ elemental analyzer. Wide-angle X-ray diffraction (WXRD) was conducted on a Bruker D8 Advance diffractometer from 6 to $70^{\circ}$ at a scanning rate of $0.5^{\circ} \mathrm{min}^{-1}$. Density was obtained using a Mettler-Toledo balance equipped with a density measurement kit based on Archimedes' principle using iso-octane as the reference liquid. The BET surface area of the polymers was measured by $\mathrm{N}_{2}$ adsorption at $-196{ }^{\circ} \mathrm{C}$ (Micrometrics ASAP 2020 with micropore option); each sample was degassed at $150{ }^{\circ} \mathrm{C}$ for $12 \mathrm{~h}$ before testing. Dynamic mechanical stress-strain curves of the polymers were measured using a dynamic mechanical analyzer (DMA, TA Instruments Q800). The samples were kept at $35^{\circ} \mathrm{C}$ for one minute and then ramped at $3 \mathrm{~N} / \mathrm{min}$ to $18 \mathrm{~N}$.

The detailed synthetic procedures of the intermediates, monomers and polymers are shown in

\section{Scheme 1.}

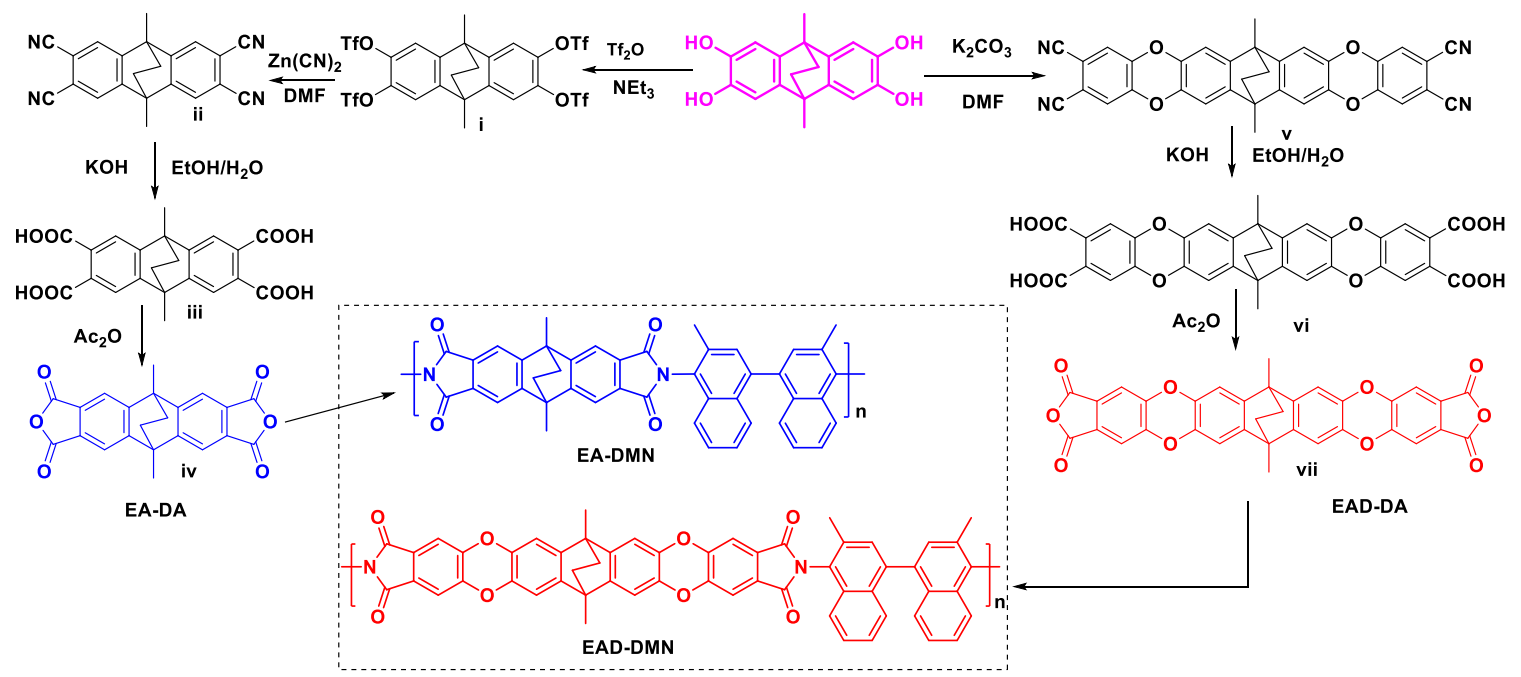


Scheme 1: Synthetic procedures of ethanoanthracene-based dianhydrides (EA-DA, iv) and (EAD-DA, vii) and their corresponding intrinsically microporous polyimides (EA-DMN and EAD-DMN).

\section{Synthesis of ethanoanthracene dianhydride (EA-DA).}

\section{9,10-Dimethylethanoanthracene-2,3,6,7-tetra-trifluoromethylsulfonate \\ (i). $\quad 9,10-$}

Dimethylethanoanthracene-2,3,6,7-tetraol $(9.00 \mathrm{~g}, 30.2 \mathrm{mmol})$ was added to the mixed solvent system of dichloromethane $(260 \mathrm{~mL})$ and triethyl amine $(40.0 \mathrm{~mL}, 337 \mathrm{mmol})$. The solution was cooled in an ice bath for $30 \mathrm{~min}$. To it, trifluoromethanesulfonic anhydride $(59.0 \mathrm{~mL}, 349 \mathrm{mmol})$ was added dropwise over $30 \mathrm{~min}$. The solution was stirred at room temperature for $4 \mathrm{~h}$ and then poured into ice water $(300 \mathrm{~mL})$. The organic phase was separated using a separatory funnel and washed several times with diluted $\mathrm{HCl}(2 \mathrm{~N})$ and then dried with anhydrous magnesium sulfate. The solvent was removed by rota-evaporation and the residual was loaded to a column. An offwhite powder (13.0 g, yield: 52.1\%) was obtained after column chromatography. TLC: dichloromethane/petroleum ether $=1 / 2, \mathrm{R}_{\mathrm{f}}=0.6 ;{ }^{1} \mathrm{H} \mathrm{NMR}\left(400 \mathrm{MHz}, \mathrm{CDCl}_{3}\right): \delta 7.40(\mathrm{~s}, 4 \mathrm{H})$, $2.03(\mathrm{~s}, 6 \mathrm{H}), 1.77(\mathrm{~s}, 4 \mathrm{H})$.

9,10-Dimethylethanoanthracene-2,3,6,7-tetracyano (ii). The intermediate i (14.5 g, 17.6 $\mathrm{mmol}), \mathrm{Zn}(\mathrm{CN})_{2}(1.50 \mathrm{~g}, 12.8 \mathrm{mmol}), \mathrm{Pd}_{2}(\mathrm{dba})_{3}(800 \mathrm{mg}, 0.76 \mathrm{mmol})$ and DPPF (1.60 g, 2.89 mmol) were added to anhydrous DMF $(80 \mathrm{~mL})$. The system was degassed under vacuum, filled with $\mathrm{N}_{2}$, and then heated to $100{ }^{\circ} \mathrm{C}$ to form a clear solution. Three $1.5 \mathrm{~g}$ portions of $\mathrm{Zn}(\mathrm{CN})_{2}$ were added in sequence to the reaction system in $1 \mathrm{~h}$. The solution was kept at $100{ }^{\circ} \mathrm{C}$ for an additional hour and then poured into methanol $(200 \mathrm{~mL})$. A yellow solid was formed, filtrated and loaded to a column. An off-white product (5.10 g, yield: $86.8 \%$ ) was obtained after column 
separation. TLC: dichloromethane, $\mathrm{R}_{\mathrm{f}}=0.3 ;{ }^{1} \mathrm{H}$ NMR $\left(400 \mathrm{MHz}, \mathrm{DMSO}-d_{6}\right): \delta 8.15(\mathrm{~s}, 4 \mathrm{H})$, $2.05(\mathrm{~s}, 6 \mathrm{H}), 1.66(\mathrm{~s}, 4 \mathrm{H})$.

9,10-Dimethylethanoanthracene-2,3,6,7-tetracarboxylic acid (iii). The tetracyano intermediate (ii) $(1.78 \mathrm{~g}, 5.33 \mathrm{mmol})$ was dispersed in ethanol $(30 \mathrm{~mL})$. To it, $\mathrm{KOH}(6.18 \mathrm{~g}, 107$ mmol) dissolved in water $(30 \mathrm{~mL})$ was added dropwise. The reaction system was heated and refluxed for $24 \mathrm{~h}$. The solution was cooled to room temperature, poured into cold $\mathrm{HCl}$ (6N, 100 $\mathrm{mL}$ ) and then stirred at room temperature for $2 \mathrm{~h}$. The precipitate was filtrated and washed three times with diluted $\mathrm{HCl}(2 \mathrm{~N})$. An off-white solid (1.30 g, yield: $62.8 \%)$ was obtained after drying at $70{ }^{\circ} \mathrm{C}$ in an oven for 12 hours. ${ }^{1} \mathrm{H}$ NMR (400 MHz, DMSO- $\left.d_{6}\right): \delta 13.1(\mathrm{~s}, 4 \mathrm{H}), 7.61(\mathrm{~s}, 4 \mathrm{H})$, $2.01(\mathrm{~s}, 6 \mathrm{H}), 1.65(\mathrm{~s}, 4 \mathrm{H})$.

9,10-Dimethylethanoanthracene-2,3,6,7-tetracarboxylic anhydride (iv). 9,10Dimethylethanoanthracene-2,3,6,7-tetracarboxylic acid ( iii, $400 \mathrm{mg}, 0.97 \mathrm{mmol}$ ) was added to acetic anhydride $(1.0 \mathrm{~mL})$. The system was heated to $120^{\circ} \mathrm{C}$ and kept for $4 \mathrm{~h}$. An off-white precipitate was collected by filtration and washed three times with cold acetic anhydride. The white powder was fully dried under vacuum at $120{ }^{\circ} \mathrm{C}$ (300 mg, yield: $\left.80.2 \%\right)$ and was directly used for polymerization reactions. ${ }^{1} \mathrm{H}$ NMR $\left(500 \mathrm{MHz}, \mathrm{CDCl}_{3}\right): \delta 7.97(\mathrm{~s}, 4 \mathrm{H}), 2.19(\mathrm{~s}, 6 \mathrm{H}), 1.80$ (s, 4H). ${ }^{13} \mathrm{C} \mathrm{NMR}\left(125 \mathrm{MHz}, \mathrm{CDCl}_{3}\right): \delta 162.8,153.7,129.9,118.3,44.3,34.3,18.5$; HRMS for [ $\left.\mathrm{C}_{22} \mathrm{H}_{15} \mathrm{O}_{6}\right]^{+}$: Calcd.: 375.0863; Found: 375.0863; Anal. Calcd. for $\mathrm{C}_{22} \mathrm{H}_{14} \mathrm{O}_{6}$ : C, 70.59; H, 3.77. Found: C, 70.20; H, 3.56.

\section{Synthesis of dibenzodioxane-containing ethanoanthracene dianhydride (EAD-DA).}

Intermediate (v). 9,10-Dimethylethanoanthracene-2,3,6,7-tetraol (5.00 g, $16.8 \mathrm{mmol})$ and 4,5-dichlorophthalonitrile $(7.27 \mathrm{~g}, 36.7 \mathrm{mmol})$ were added to anhydrous DMF (60 mL) under nitrogen. The solution was heated to $80{ }^{\circ} \mathrm{C}$ and stirred for $30 \mathrm{~min}$. To the brown solution, 
potassium carbonate $(15.0 \mathrm{~g}, 108 \mathrm{mmol})$ was added in portions over $5 \mathrm{~min}$. The system was kept at $80{ }^{\circ} \mathrm{C}$ for $3 \mathrm{~h}$ during which precipitation occurred. The solid was filtered, washed in sequence with water, ethanol and dichloromethane, and then refluxed with $50 \mathrm{~mL}$ dichloromethane three times. The product was obtained as an off-white solid (7.80 g, yield: $85 \%)$ after drying under vacuum at $120{ }^{\circ} \mathrm{C}$ for $8 \mathrm{~h} .{ }^{1} \mathrm{H}$ NMR (400 MHz, DMSO- $\left.d_{6}\right): \delta 7.80(\mathrm{~s}, 4 \mathrm{H}), 6.92(\mathrm{~s}, 4 \mathrm{H}), 1.80(\mathrm{~s}$, $6 \mathrm{H}), 1.51(\mathrm{~s}, 4 \mathrm{H})$.

Intermediate (vi). The intermediate $\mathbf{v}(4.50 \mathrm{~g}, 8.24 \mathrm{mmol})$ was dispersed in ethanol $(60 \mathrm{~mL})$. To it, a solution of $\mathrm{KOH}(9.56 \mathrm{~g}(164.8 \mathrm{mmol})$ dissolved in $60 \mathrm{~mL}$ water was added dropwise. The system was refluxed overnight and a clear solution was formed. After filtration, the solution was cooled to room temperature and poured into concentrated $\mathrm{HCl}(6 \mathrm{M}, 50 \mathrm{~mL})$. An off-white precipitate was formed, which was filtrated and washed with diluted $\mathrm{HCl}(1 \mathrm{M})$ three times. The solid was re-dissolved in THF and precipitated in a large amount of DCM. A light yellow solid (4.0 g, yield: $78.0 \%$ ) was obtained after drying under vacuum at $60{ }^{\circ} \mathrm{C}$ for $24 \mathrm{~h} .{ }^{1} \mathrm{H}$ NMR $(400$ MHz, DMSO- $\left.d_{6}\right): \delta 7.18(\mathrm{~s}, 4 \mathrm{H}), 6.87(\mathrm{~s}, 4 \mathrm{H}), 1.80(\mathrm{~s}, 6 \mathrm{H}), 1.52(\mathrm{~s}, 4 \mathrm{H})$.

Dibenzodioxane-containing ethanoanthracene dianhydride (vii) The tetracarboxylic acid intermediate vi $(2.00 \mathrm{~g}, 3.21 \mathrm{mmol})$ was added to acetic anhydride $(15 \mathrm{~mL})$. The system was refluxed at $120{ }^{\circ} \mathrm{C}$ for overnight. A light yellow solid was precipitated in acetic anhydride, filtrated and washed with acetic anhydride three times. The product (1.87 g, yield: $99.4 \%)$ was obtained after drying under vacuum at $120{ }^{\circ} \mathrm{C}$ for $12 \mathrm{~h} .{ }^{1} \mathrm{H}$ NMR $\left(400 \mathrm{MHz}, \mathrm{CDCl}_{3}\right): \delta 7.36(\mathrm{~s}$, 4H), $6.86(\mathrm{~s}, 4 \mathrm{H}), 1.89(\mathrm{~s}, 6 \mathrm{H}), 1.64(\mathrm{~s}, 4 \mathrm{H}) .{ }^{13} \mathrm{C} \mathrm{NMR}\left(125 \mathrm{MHz}, \mathrm{CDCl}_{3}\right): \delta$ 161.7, 149.0, 143.0, 137.9, 127.3, 113.2, 109.8, 41.4, 35.3, 18.3; HRMS for $\mathrm{C}_{34} \mathrm{H}_{18} \mathrm{O}_{10}$ : Calcd.: 586.0900; Found. 586.0878; Anal. Calcd. for $\mathrm{C}_{34} \mathrm{H}_{18} \mathrm{O}_{10}$ : C, 69.63; H, 3.09. Found: C, 68.79; H, 2.93. 
Synthesis of EA-DMN polyimide. EA-DA (196.6 $\mathrm{mg}, 0.526 \mathrm{mmol})$ and 3,3dimethylnaphthidine (164.2 $\mathrm{mg}, 0.526 \mathrm{mmol})$ were added to $m$-cresol $(1.9 \mathrm{~mL})$ under $\mathrm{N}_{2}$ flow. The system was heated to $60{ }^{\circ} \mathrm{C}$ and kept for $1 \mathrm{~h}$ to form a viscous solution. One drop of isoquinoline was added and the solution was heated to $180{ }^{\circ} \mathrm{C}$ and kept under stirring for $3 \mathrm{~h}$. A highly viscous solution was formed and precipitated into methanol (100 $\mathrm{mL})$. The remaining $m$ cresol was removed by Soxhlet extraction using methanol. The polymer was dissolved in chloroform and precipitated in methanol twice. An off-white powder (340 mg, yield: 94.5\%) was obtained after drying under vacuum for $24 \mathrm{~h}$ at $120{ }^{\circ} \mathrm{C} .{ }^{1} \mathrm{H}$ NMR $\left(500 \mathrm{MHz}, \mathrm{CDCl}_{3}\right): \delta 8.10(\mathrm{~s}$, 4H), 7.26-7.65 (m, 10H), 2.30-2.45 (m, 12H), 2.04 (s, 4H). FT-IR (polymer film, v, $\left.\mathrm{cm}^{-1}\right): 3055$ (m, str C-H), 1780, 1714 (s, str, imide), 1600, 1452 (m, str, Ph), 1311, 1286 (s, str, C-N), 747 (s, asy, imide); Anal. Calcd. for $\mathrm{C}_{44} \mathrm{H}_{30} \mathrm{~N}_{2} \mathrm{O}_{4}: \mathrm{C}, 80.96 ; \mathrm{H}, 4.94 ; \mathrm{N}, 4.29$. Found: $\mathrm{C}, 78.08 ; \mathrm{H}, 4.60$; $\mathrm{N}, 3.80$; Molecular weight (GPC in chloroform) $\mathrm{M}_{\mathrm{n}}=13 \times 10^{4} \mathrm{~g} \mathrm{~mol}^{-1} ; \mathrm{PDI}=2.1 . \mathrm{T}_{\mathrm{d}}=300{ }^{\circ} \mathrm{C}$; $\mathrm{S}_{\mathrm{BET}}=720 \mathrm{~m}^{2} \mathrm{~g}^{-1}$.

Synthesis of EAD-DMN polyimide. The synthetic procedure for EAD-DMN followed the same protocol as that of EA-DMN. The polymer was obtained as yellow filaments with a yield of 93.5\%. ${ }^{1} \mathrm{H}$ NMR (400 MHz, $\left.\mathrm{CDCl}_{3}\right): \delta 7.65$ (s, 2H), 7.49-7.63 (m, 10H), 7.37 (s, 2H), 6.95 (s, 4H), $2.46(\mathrm{~s}, 6 \mathrm{H}), 1.97$ (s, 2H), $1.30(\mathrm{~s}, 4 \mathrm{H})$. FT-IR (polymer film, $\left.v, \mathrm{~cm}^{-1}\right): 3067$ (m, str C-H), 2960 (m, str Me-), 1778, 1714 (s, str, imide), 1600, 1466, 1351 (m, str, Ph), 1311, 1286 (s, str, CN), 747 (s, asy, imide); Anal. Calcd. for $\mathrm{C}_{56} \mathrm{H}_{34} \mathrm{~N}_{2} \mathrm{O}_{8}$ : C, 77.77; H, 4.20; N, 3.24; Found: C, 76.52; $\mathrm{H}, 4.23 ; \mathrm{N}, 2.98$; Molecular weight (GPC in chloroform) $\mathrm{M}_{\mathrm{n}}=6.0 \times 10^{4} \mathrm{~g} \mathrm{~mol}^{-1} ; \mathrm{PDI}=2.7 . \mathrm{T}_{\mathrm{d}}=$ $300{ }^{\circ} \mathrm{C} ; \mathrm{S}_{\mathrm{BET}}=800 \mathrm{~m}^{2} \mathrm{~g}^{-1}$.

Polymer film formation. The polymers were dissolved in chloroform $(2 \sim 3 \% \mathrm{wt} / \mathrm{v})$ and the solutions were purified using 1- $\mu \mathrm{m}$ PTFE filter cartridges. The solution was carefully poured 
into a flat Petri dish supported by a leveled glass plate. The solvent was evaporated slowly over several days at ambient conditions. Light yellow polymer films were soaked in methanol for $24 \mathrm{~h}$, air-dried for $24 \mathrm{~h}$ and then mounted in the permeation cell. Prior to gas permeation testing the samples were degassed under high vacuum $\left(1.5 \times 10^{-4} \mathrm{cmHg}\right)$ for at least $24 \mathrm{~h}$ at $35^{\circ} \mathrm{C}$ to remove any potential traces of methanol. The sequence of equilibrium methanol conditioning in the PIMPIs and demonstration of complete solvent removal by the above procedure is shown in Table S1. All samples used for aging studies were stored in a desiccator under vacuum using an oil-free pump to avoid contamination of the polyimides with oil mist.

Gas permeation tests. Pure-gas permeability of the polyimides for $\mathrm{H}_{2}, \mathrm{~N}_{2}, \mathrm{O}_{2}, \mathrm{CH}_{4}$ and $\mathrm{CO}_{2}$ was determined by the constant-volume/variable-pressure method at 2 bar and $35{ }^{\circ} \mathrm{C}$. Details are provided in the Supporting Information.

\section{RESULTS AND DISCUSSION}

Synthesis and Characterization of Physical Properties. The synthesis and gas permeation properties of the ethanoanthracene dianhydride-DMN-based polyimide (PIM-PI-EA or PIM-PI12) were first reported by Mckeown's group. ${ }^{25}$ The ethanoanthracene dianhydride (EA-DA) was obtained from 4-bromo-1,2-dimethylbenzene and 2,5-hexanedione as starting materials using a four-steps reaction. In this work, we used a different synthetic protocol for the synthesis of EADA which was also applied for the preparation of a novel, dibenzodioxane-containing ethanoanthracene dianhydride (EAD-DA) made from the same starting material, biscatecol (9,10-dimethyl-ethanoanthracene-2,3,6,7-tetraol), as shown in Scheme 1. The synthesis of EADA, iv, started from 9,10-dimethyl-ethanoanthracene-2,3,6,7-tetraol, which was reacted with triflic anhydride to form the tetra-triflate intermediate (i). The pseudo-halide 
trifluoromethanesulfonyl group was substituted with a cyano group by reaction with $\mathrm{Zn}(\mathrm{CN})_{2}$ using a palladium catalyst. $^{26}$ The formation of the 9,10-dimethyl-2,3,6,7tetracyanoethanoanthracene (ii) was highly efficient ( $2 \mathrm{~h}$ and $86 \%$ yield). This tetracyano intermediate (ii) underwent further hydrolysis using potassium hydroxide. The final dianhydride product iv, (EA-DA), was obtained by reflux with acetic anhydride of intermediate iii.

The synthetic procedure of the dibenzodioxane-containing ethanoanthracene-based dianhydride (EAD-DA, vii) is also shown in Scheme 1. 9, 10-Dimethylethanoanthracene-2, 3, 6, 7-tetraol was reacted with 4, 5-dichlorophthalonitrile to form the tetracyano intermediate (v) by aromatic substitution (SNAr) reaction, which was converted to the corresponding tetracarboxylic acid intermediate (vi) by hydrolysis in potassium hydroxide solution. EAD-DA (vii) was then obtained under reflux in acetic anhydride.

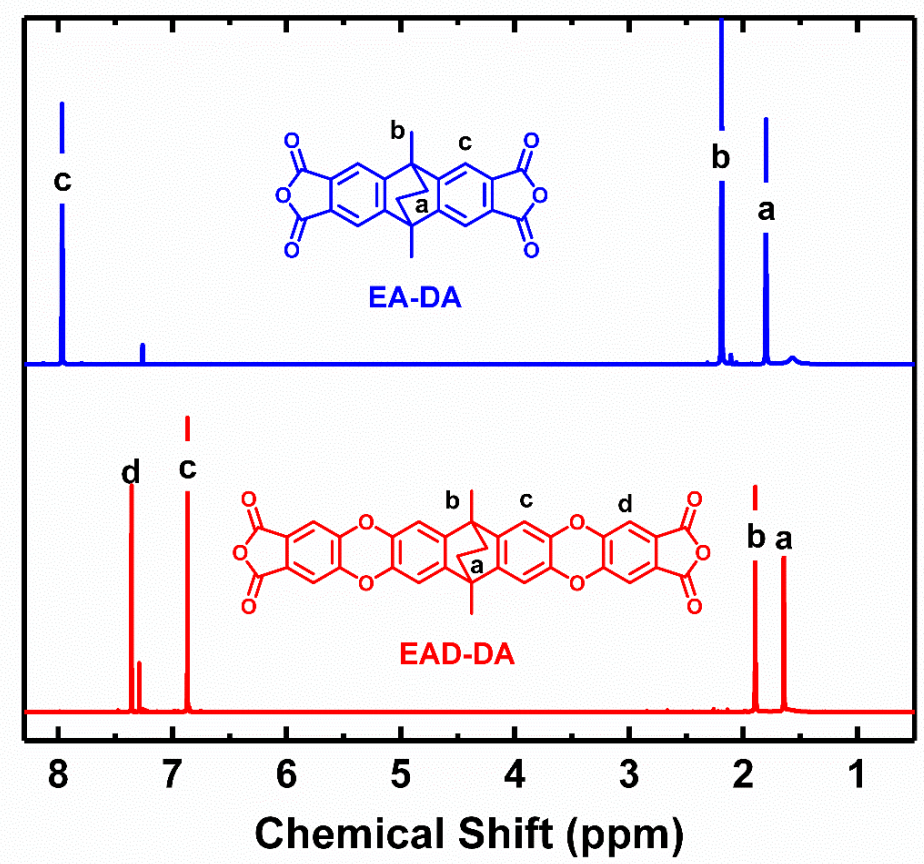

Figure 1. Proton NMR spectra of the ethanoanthracene-based dianhydrides (EA-DA and EADDA). 
The chemical structures of the dianhydrides (EA-DA and EAD-DA) were confirmed by their ${ }^{1}$ H NMR spectra (Figure 1) and HRMS. The short dianhydride, EA-DA, demonstrated chemical shifts towards lower field for all protons as compared with the more extended, dibenzodioxanecontaining dianhydride (EAD-DA), as shown in Figure 1. This result indicates stronger electronic effects of the anhydride groups in EA-DA than in EAD-DA.

The two dianhydrides were reacted with 3,3'-dimethylnaphthidine (DMN) in $m$-cresol under catalytic amount of isoquinoline. The basic properties of the resulting polyimides, EA-DMN and EAD-DMN, are summarized in Table 1. Both polymers were readily soluble in conventional solvents such as chloroform, DMF, DMAc, NMP and $m$-cresol. EA-DMN and EAD-DMN demonstrated high $\mathrm{M}_{\mathrm{n}}$ of 130,000 and 60,000 $\mathrm{g} \mathrm{mol}^{-1}$ and low polydispersity index (PDI) of 2.1 and 2.7 , respectively.

Table 1. Basic Properties of EA-DMN and EAD-DMN Polyimides.

\begin{tabular}{lccccc}
\hline Polymer & $\begin{array}{c}\mathrm{M}_{\mathrm{n}} \times 10^{a} \\
\left(\mathrm{~g} \mathrm{~mol}^{-1}\right)\end{array}$ & $\begin{array}{c}\text { PDI } \\
(-)\end{array}$ & $\begin{array}{c}\mathrm{T}_{\mathrm{d}}^{b} \\
\left({ }^{\circ} \mathrm{C}\right)\end{array}$ & $\begin{array}{c}\mathrm{S}_{\mathrm{BET}} \\
\left(\mathrm{m}^{2} \mathrm{~g}^{-1}\right)\end{array}$ & $\begin{array}{c}\text { Density } \\
\left(\mathrm{cm}^{3} \mathrm{~g}^{-1}\right)\end{array}$ \\
\hline EA-DMN & 130,000 & 2.1 & $300(520)^{c}$ & $720(616)^{d}$ & 1.18 \\
EAD-DMN & 60,000 & 2.7 & $300(520)^{c}$ & 800 & 1.17 \\
\hline
\end{tabular}
decomposition temperature; ${ }^{c}$ number in the bracket is the decomposition temperature of the second degradation stage (Figure 2); ${ }^{d}$ BET surface area in the bracket is from reference 25 .

Both ethanoanthracene-based polyimides showed high thermal stability (Figure 2); however, an initial weight loss started at $\sim 300{ }^{\circ} \mathrm{C}$ due to retro Diels-Alder reaction by decomposing the unstable ethylene dienophile in the ethanoanthracene moiety. This phenomenon has been well documented for anthracene-based polymers. ${ }^{27-29}$ Both PIM-PIs showed $\sim 5$ wt $\%$ weight loss between $\sim 300$ to $\sim 520{ }^{\circ} \mathrm{C}$, after which main chain degradation started to occur. 


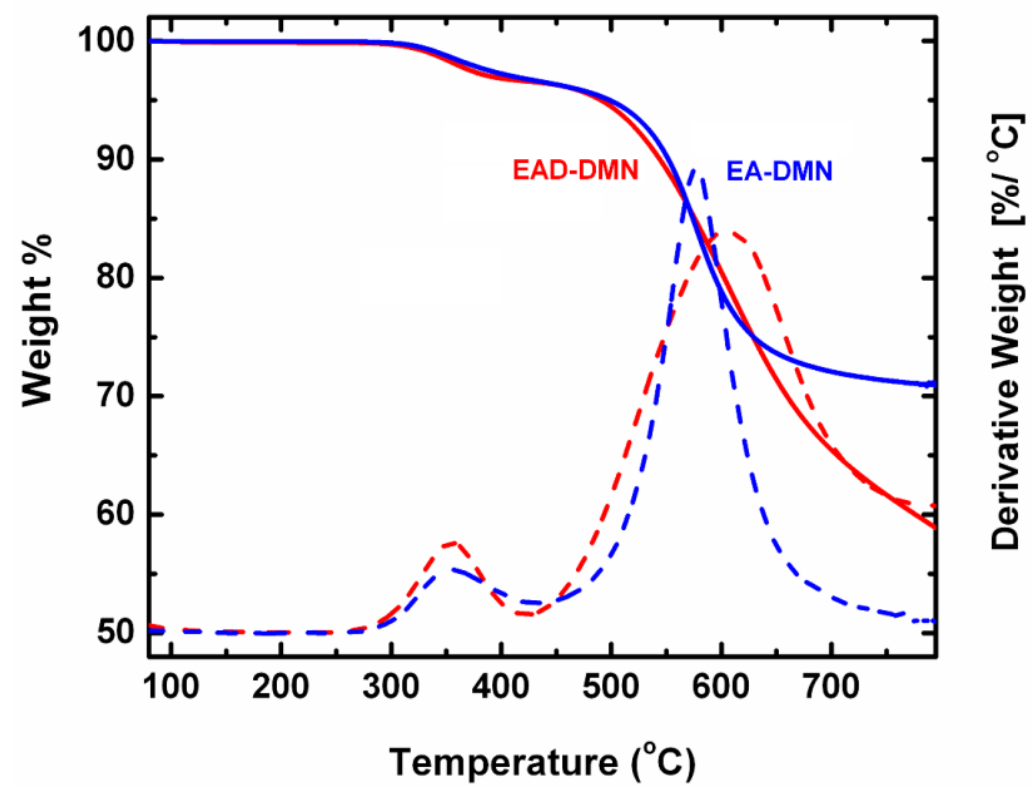

Figure 2. TGA scans and weight loss derivatives of EA-DMN (blue) and EAD-DMN (red) polyimides.

The adsorption/desorption isotherms determined with $\mathrm{N}_{2}$ at $-196{ }^{\circ} \mathrm{C}$ up to 1 bar are illustrated in Figure 3. EA-DMN and EAD-DMN exhibited remarkable microporosity with very high BET surface areas of 720 and $800 \mathrm{~m}^{2} \mathrm{~g}^{-1}$, respectively. Previously, a lower BET surface area of 616 $\mathrm{m}^{2} \mathrm{~g}^{-1}$ was reported for EA-DMN ${ }^{25}$ which could have possibly resulted from different drying conditions of the polymer samples. Both polyimides were amorphous and had large average dspacing values as determined by Bragg's law from their wide angle X-ray scattering spectra shown in Figure 4. The EA-DMN polyimide exhibited a more tightly arranged chain structure than EAD-DMN, as indicated by average d-spacing values of 6.20 and $6.89 \AA$, respectively (Figure 4). 


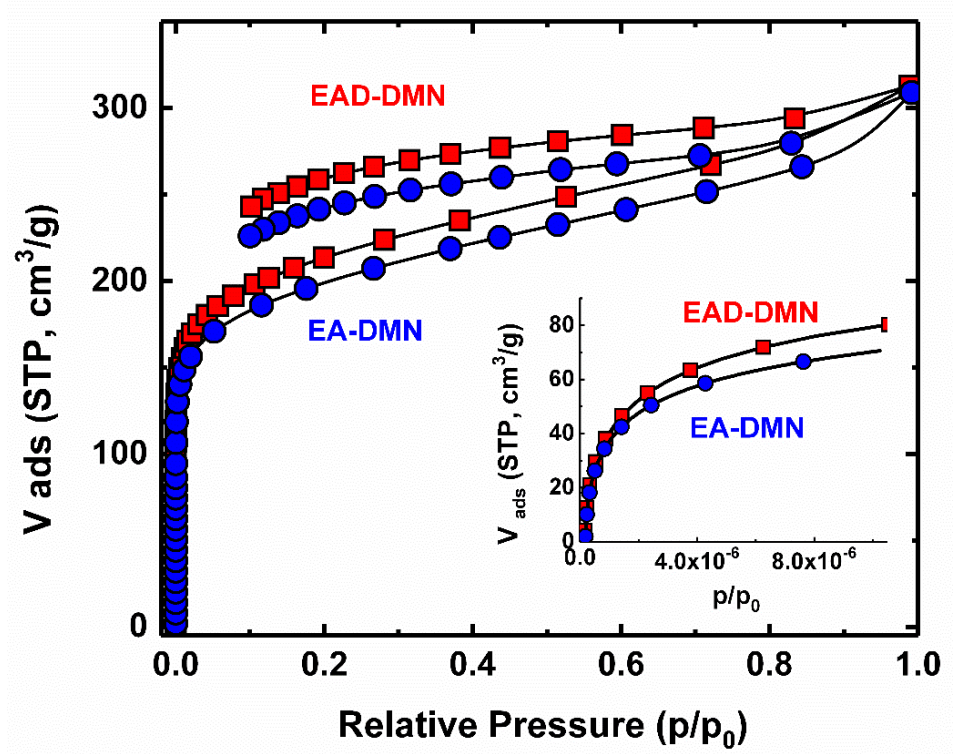

Figure 3. $\mathrm{N}_{2}$ adsorption/desorption isotherms of EA-DMN (blue) and EAD-DMN (red) at $196{ }^{\circ} \mathrm{C}$ up to 1 bar. The inside graph shows $\mathrm{N}_{2}$ adsorption isotherms of EA-DMN and EADDMN at very low relative pressure $\left(\mathrm{p} / \mathrm{p}_{0}<10^{-5}\right)$.

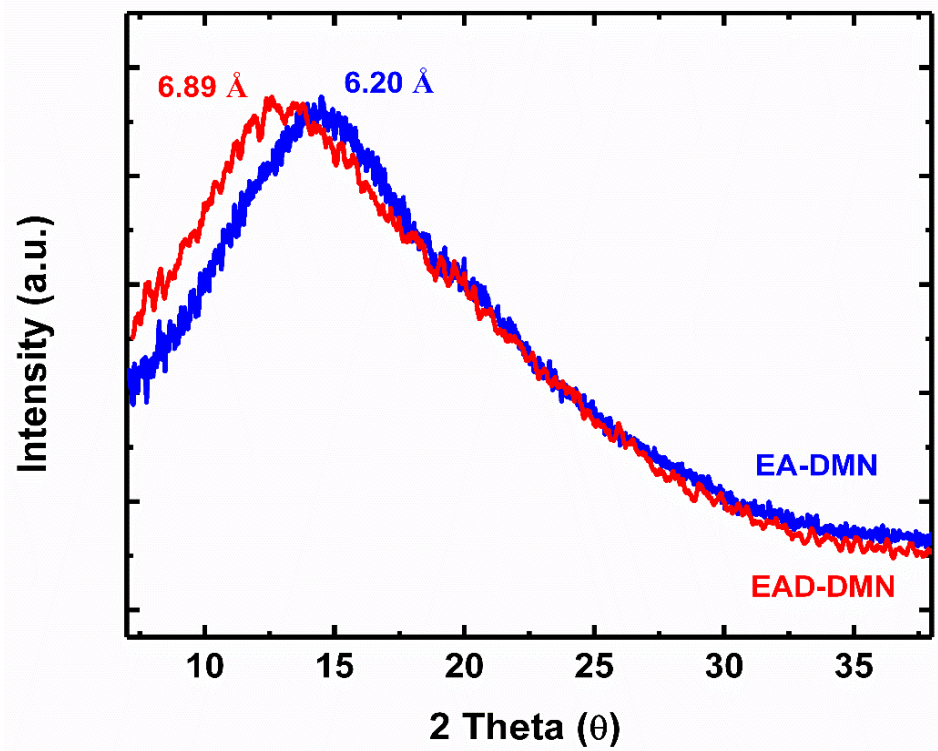

Figure 4. Wide-angle X-ray diffraction spectra of EA-DMN and EAD-DMN films. Zerobackground crystal silica was used as a support. 
Gas permeation properties of EA-DMN and EAD-DMN polyimides. The gas permeation properties of the polyimide films were determined for $\mathrm{H}_{2}, \mathrm{O}_{2}, \mathrm{~N}_{2}, \mathrm{CH}_{4}$ and $\mathrm{CO}_{2}$ at $35{ }^{\circ} \mathrm{C}$ and 2 bar upstream pressure by the constant-volume/variable-pressure technique (ESI). The results are summarized in Table 2.

Table 2. Gas Permeability and Gas-Pair Selectivity of EA-DMN and EAD-DMN Polyimide Films with Different Thickness and Aging Time at $35^{\circ} \mathrm{C}$ and 2 bar Upstream Pressure.

\begin{tabular}{|c|c|c|c|c|c|c|c|c|c|}
\hline \multirow{2}{*}{ Polymer } & \multicolumn{5}{|c|}{ Permeability (Barrer) } & \multicolumn{4}{|c|}{ Ideal selectivity $\left(\alpha_{X / Y}\right)$} \\
\hline & $\mathrm{H}_{2}$ & $\mathrm{~N}_{2}$ & $\mathrm{O}_{2}$ & $\mathrm{CH}_{4}$ & $\mathrm{CO}_{2}$ & $\mathrm{H}_{2} / \mathrm{N}_{2}$ & $\mathrm{O}_{2} / \mathrm{N}_{2}$ & $\mathrm{H}_{2} / \mathrm{CO}_{2}$ & $\mathrm{CO}_{2} / \mathrm{CH}_{4}$ \\
\hline $\begin{array}{l}\text { EA-DMN-72 } \mu \mathrm{m}^{a} \\
1 \text { day }\end{array}$ & 4230 & 369 & 1380 & 457 & 7340 & 11.5 & 3.7 & 0.58 & 16.1 \\
\hline Aged 273 days & 2860 & 131 & 659 & 156 & 3230 & 21.8 & 5.0 & 0.89 & 20.7 \\
\hline $\begin{array}{l}\text { EA-DMN- } 123 \mu \mathrm{m}^{b} \\
1 \text { day }\end{array}$ & 4522 & 320 & 1314 & 379 & 6520 & 14.1 & 4.1 & 0.69 & 17.2 \\
\hline Aged 180 days & 3067 & 162 & 739 & 185 & 3603 & 19.0 & 4.6 & 0.85 & 19.5 \\
\hline $\begin{array}{l}\text { EA-DMN-60 } \mu \mathrm{m}^{b} \\
1 \text { day }\end{array}$ & 3291 & 165 & 783 & 154 & 3321 & 20.0 & 4.8 & 0.99 & 21.6 \\
\hline $\begin{array}{l}\text { EA-DMN-40 } \mu \mathrm{m}^{b} \\
1 \text { day }\end{array}$ & 2261 & 77 & 409 & 78 & 1783 & 29.2 & 5.3 & 1.27 & 22.8 \\
\hline $\begin{array}{l}\text { EA-DMN-15 } \mu \mathrm{m}^{b} \\
1 \text { day }\end{array}$ & 1844 & 42 & 263 & 45 & 1100 & 43.9 & 5.6 & 1.68 & 24.6 \\
\hline $\begin{array}{l}\text { EAD-DMN-172 } \mu \mathrm{m}^{b} \\
1 \text { day }\end{array}$ & 4703 & 480 & 1586 & 707 & 8070 & 9.8 & 3.3 & 0.58 & 11.4 \\
\hline Aged 180 days & 3476 & 261 & 969 & 354 & 5197 & 13.3 & 3.7 & 0.67 & 14.7 \\
\hline Aged 430 days & 3171 & 226 & 863 & 305 & 4480 & 14.1 & 3.8 & 0.71 & 14.7 \\
\hline $\begin{array}{l}\text { EAD-DMN-70 } \mu \mathrm{m}^{b} \\
1 \text { day }\end{array}$ & 2856 & 171 & 655 & 225 & 3500 & 16.7 & 3.8 & 0.82 & 15.5 \\
\hline Aged 400 days & 1996 & 78 & 374 & 93 & 1788 & 25.5 & 4.8 & 1.12 & 19.2 \\
\hline $\begin{array}{l}\text { EAD-DMN-39 } \mu \mathrm{m}^{b} \\
1 \text { day }\end{array}$ & 2121 & 111 & 511 & 136 & 2502 & 19.1 & 4.6 & 0.85 & 18.4 \\
\hline Aged 80 days & 1409 & 52 & 261 & 61 & 1124 & 26.9 & 5.0 & 1.25 & 18.4 \\
\hline $\begin{array}{l}\text { EAD-DMN-23 } \mu \mathrm{m}^{b} \\
1 \text { day }\end{array}$ & 1289 & 43 & 213 & 55 & 979 & 29.9 & 4.9 & 1.32 & 17.8 \\
\hline Aged 50 days & 830 & 21 & 113 & 26 & 471 & 39.5 & 5.4 & 1.71 & 18.3 \\
\hline
\end{tabular}


${ }^{a}$ Air dried film, methanol-treated, air dried; tested at $25{ }^{\circ} \mathrm{C}$ under pressure of 1 bar (from reference 25).

${ }^{b}$ Air dried film, methanol treated for $24 \mathrm{~h}$, air dried for $24 \mathrm{~h}$ and dried under vacuum at $35{ }^{\circ} \mathrm{C}$ for $24 \mathrm{~h}$ prior to permeation testing; tested at $35^{\circ} \mathrm{C}$ under pressure of $2 \mathrm{bar}$.

The gas permeation properties of ladder PIMs and PIM-PIs are strongly dependent on: i) film formation protocol, i.e. solvent type and drying conditions, ii) post-solvent treatment (typically methanol or ethanol), (iii) film thickness and (iv) aging time. ${ }^{16,18,19,20}$ All EA-DMN and EADDMN polyimide films in this study were made by the same protocol: i) solution casting from chloroform solution in a Petri dish, (ii) drying under ambient conditions for several days, (iii) soaking in methanol for $24 \mathrm{~h}$ and (iv) air drying for $24 \mathrm{~h}$ and (v) final drying at $35{ }^{\circ} \mathrm{C}$ under vacuum in the permeation system. Previous studies on the archetypal ladder polymer of intrinsic microporosity (PIM-1) demonstrated that methanol conditioning removed all residual solvent and led to swelling-induced relaxation of the polymer chains with a commensurate increase in free volume. ${ }^{20}$ Similar to PIM-1, films of EA-DMN and EAD-DMN also showed an increase in thickness and decrease in area upon methanol treatment and drying (Table S2).

In a first set of experiments, the effect of thickness of fresh, 1-day-old PIM-PI films on their gas permeation properties was investigated, as shown in Table 2. Similar to previously reported results for an ethanoanthracene-Tröger's base ladder polymer (PIM-EA-TB) by Carta et al., ${ }^{6}$ thickness dependent effects on permeability and selectivity were significant for EA-DMN and EAD-DMN polyimides. For example, a fresh $123-\mu$ m-thick EA-DMN film exhibited an $\mathrm{O}_{2}$ permeability of 1314 Barrer and $\mathrm{O}_{2} / \mathrm{N}_{2}$ selectivity of 4.1 , whereas a fresh $15-\mu \mathrm{m}$-thick sample showed $80 \%$ reduction in $\mathrm{O}_{2}$ permeability to 263 Barrer with a commensurate increase in $\mathrm{O}_{2} / \mathrm{N}_{2}$ selectivity to 5.6. For comparison, Rogan et al. previously reported an $\mathrm{O}_{2}$ permeability of 1380 
Barrer and $\mathrm{O}_{2} / \mathrm{N}_{2}$ selectivity of 3.7 for a fresh, methanol-treated and air dried $72-\mu \mathrm{m}$-thick EADMN film (Table 2) ${ }^{25}$ Upon aging over 273 days, the $\mathrm{O}_{2}$ permeability dropped by $\sim 50 \%$ to 659 Barrer with a simultaneuous increase in $\mathrm{O}_{2} / \mathrm{N}_{2}$ selectivity to 5.0. Notably, changes in polymer chain packing for PIM-PI samples of different thickness or age can be tracked efficiently by their order in gas permeability. PIM-PIs with very high gas permeability typically follow the sequence: $\mathrm{CO}_{2}>\mathrm{H}_{2}>\mathrm{O}_{2}>\mathrm{N}_{2}>\mathrm{CH}_{4} \cdot{ }^{25,30-33}$ However, as film thickness is reduced PIM-PIs can become $\mathrm{H}_{2} / \mathrm{CO}_{2}$-selective due to a shift in polymer chain packing towards a more size-selective ultramicroporous texture, as recently shown for a carbocyclic pseudo Tröger's base-dianhydrideDMN polyimide (CTB2-DMN). ${ }^{34}$ This was also demonstrated here for fresh 1-day-old EA-DMN samples with thickness of less than $\sim 40 \mu \mathrm{m}$, as shown in Table 2. Evidently, $\mathrm{H}_{2} / \mathrm{CO}_{2}$ selectivity increased from 0.69 for a $123-\mu \mathrm{m}$-thick EA-DMN sample to $0.99,1.27$ and 1.68 for $60-, 40$ - and $15-\mu$ m-thick films. Concurrently, $\mathrm{CO}_{2}$ permeability dropped by $\sim 80 \%$ from 6500 to 1100 Barrer and $\mathrm{H}_{2}$ permeability by $60 \%$ from 4522 to 1844 Barrer by decreasing the thickness of fresh EADMN films from 123 to $15 \mu \mathrm{m}$. It is important to note that fresh EA-DMN and EAD-DMN films air-dried and then post-dried at $120{ }^{\circ} \mathrm{C}$ without a methanol-conditioning step displayed both lower gas permeabilities and gas-pair selectivities for films of similar thickness using the drying protocol noted above (Table S3). The differences in gas permeation properties resulted most likely from trapped casting solvent, chloroform, in the micropores of the polyimides (Table S2).

The effect of physical aging on the gas permeation properties of a $123-\mu \mathrm{m}$-thick EA-DMN film over a period of 180 days was less pronounced as the $\mathrm{H}_{2} / \mathrm{CO}_{2}$ selectivity increased only to 0.85 from 0.69 for a fresh film. The $\mathrm{CO}_{2}$ permeability decreased by $45 \%$ from 6520 to 3603 Barrer and $\mathrm{H}_{2}$ permeability dropped by $32 \%$ from 4522 to 3067 Barrer. Our aging results are in qualitative agreement with previously reported gas permeation data for EA-DMN polyimide by 
Carta et al. ${ }^{25}$ In their study, a fresh $72-\mu$ m-thick film showed a decline in $\mathrm{CO}_{2}$ permeability from 7340 to 3230 Barrer after storage of 273 days combined with an increase in $\mathrm{H}_{2} / \mathrm{CO}_{2}$ selectivity from 0.58 to 0.89 . Clearly, gas permeability and selectivity values for the $72-\mu \mathrm{m}$-thick film after aging of 273 days were significantly different than those of the fresh 1-day old 15- $\mu$ m-thick EADMN film reported here (Table 2). This result strongly indicates that reduced thickness of freestanding, solution-cast films can lead to accelerated equilibrium chain arrangement with gas permeation properties closer to the intrinsic values of PIM-PIs.

In a second set of experiments, the qualitative trends of the effects of film thickness and physical aging were verified for the more flexible EAD-DMN polyimide based on the dibenzodioxane-containing ethanoanthracene dianhydride building block. A fresh $172-\mu \mathrm{m}$-thick EAD-DMN film showed higher gas permeabilities and lower gas-pair selectivities than a 123$\mu$ m-thick EA-DMN sample tested under the same conditions, which was consistent with the higher BET surface area of EAD-DMN. It is noteworthy that the aged 172- $\mu \mathrm{m}$-thick EAD-DMN film appeared to reach a quasi-equilibrium state after 430 days as indicated by essentially constant gas-pair selectivities and only $10-15 \%$ decrease in gas permeabilities relative to same sample tested after 180 days (Figure S1). After 430 days, the $\mathrm{O}_{2}$ permeability decreased from 1586 Barrer for the fresh film to 863 Barrer with a concurrent increase in $\mathrm{O}_{2} / \mathrm{N}_{2}$ selectivity from 3.3 to 3.8. These values would normally be reported as "intrinsic" gas permeation properties of EDA-DMN polyimide and placed on a permeability/selectivity upper bound curve. However, in line with the results obtained for the EA-DMN polyimide discussed above, thinner fresh EADDMN films $(\sim 10-30 \mu \mathrm{m})$ exhibited significantly lower gas permeabilities and higher gas-pair selectivities than thicker samples $(>100 \mu \mathrm{m}$ ) that were aged for extended periods of more than 6 months. The importance of film thickness and aging time to obtain more realistic quasi- 
equilibrium gas permeation data is clearly evidenced by comparing the properties of a $23-\mu \mathrm{m}-$ thick EAD-DMN film aged for 50 days with those of a fresh $172-\mu$ m-thick film $-\mathrm{O}_{2}$ and $\mathrm{H}_{2}$ permeabilities of the aged $23-\mu \mathrm{m}$-thick film were $\sim 14$ - and 6-fold lower than those of the thicker film with commensurate 1.6- and 4-fold increase in $\mathrm{O}_{2} / \mathrm{N}_{2}$ and $\mathrm{H}_{2} / \mathrm{N}_{2}$ selectivity from 3.3 to 5.4 and 9.8 to 39.5, respectively (Table 2).

The apparent $\mathrm{CO}_{2}, \mathrm{CH}_{4}$ and $\mathrm{N}_{2}$ diffusion and solubility coefficient values deduced from time lag measurements for fresh and 180-day aged EA-DMN and EAD-DMN samples are summarized in Table S4. Previously published data by Carta et al. ${ }^{25}$ for fresh and 273 days old EA-DMN samples are included for comparison. It is evident that the loss in permeability upon aging resulted from significant reductions in diffusion coefficients due to polymer chain packing densification, whereas only small effects on gas solubility coefficients were observed. Furthermore, consistent with BET results obtained from low temperature $\mathrm{N}_{2}$ isotherms (Figure 3), EAD-DMN showed higher gas solubility values than EA-DMN for fresh and aged samples.

The combined effects of film thickness and aging time on the gas separation performance of EA-DMN and EAD-DMN are illustrated in Figure 5 relative to $2008^{23}$ and $2015^{10}$ permeability/selectivity upper bounds for $\mathrm{O}_{2} / \mathrm{N}_{2}$ and $\mathrm{H}_{2} / \mathrm{N}_{2}$ separation. It is clear that EA-DMN displayed better overall performance than EAD-DMN as all data regardless of thickness and aging time were located closer to the 2015 upper bound lines for $\mathrm{O}_{2} / \mathrm{N}_{2}$ and $\mathrm{H}_{2} / \mathrm{N}_{2}$ separation. 

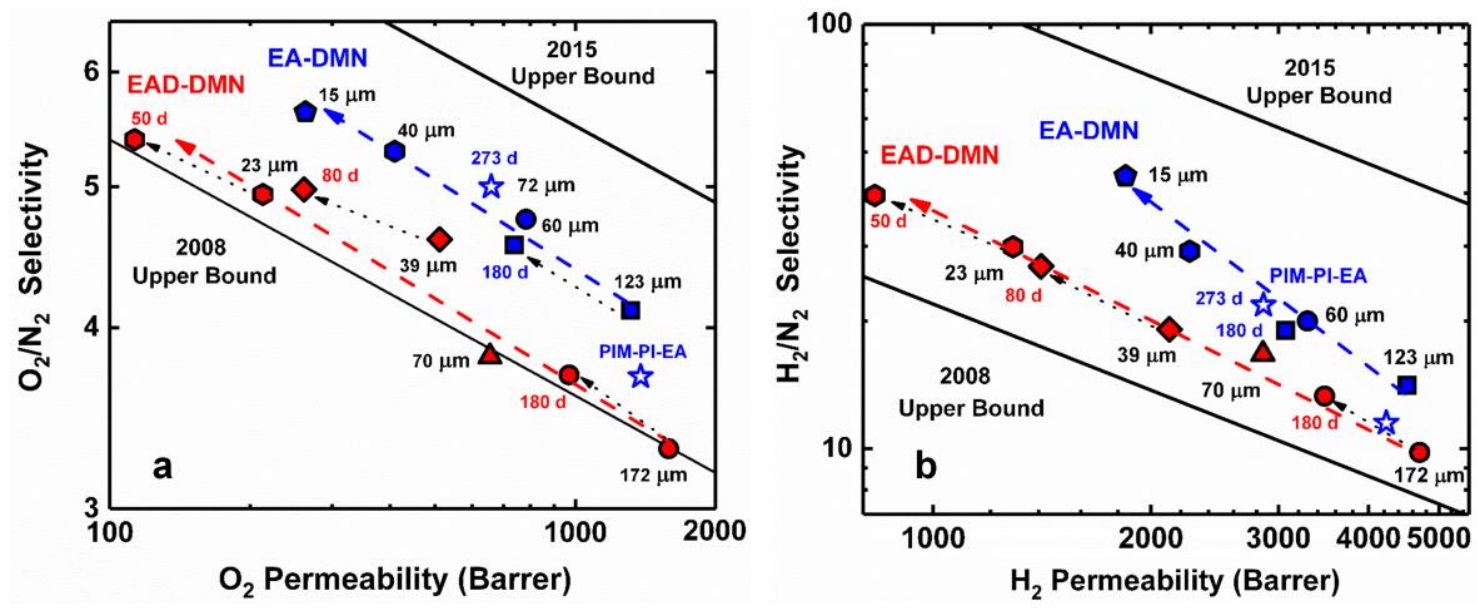

Figure 5. Performance of EA-DMN and EAD-DMN polyimide for $\mathrm{O}_{2} / \mathrm{N}_{2}$ and $\mathrm{H}_{2} / \mathrm{N}_{2}$ separation relative to the 2008 and 2015 permeability/selectivity upper bounds for films of different thickness and aging time.

The better overall gas separation performance of EA-DMN may be due to its enhanced rigidity relative to EAD-DMN polyimide, which contains dibenzodioxane moieties that provide some flexibility to the polymer backbone. ${ }^{20,21}$ The more rigid, torsion-resistant chain structure of EADMN was confirmed by evaluating the mechanical properties of the PIM-PIs based on stressstrain measurements, as shown in Figure S2 and Table S5. EA-DMN and EAD-DMN exhibited similar tensile strength $(55.4$ vs $63.1 \mathrm{MPa})$ but EAD-DMN displayed more chain flexibility as indicated by its higher elongation at break value than EA-DMN (30\% vs 15\%).

\section{CONCLUSIONS}

Two ethanoanthracene-based dianhydrides made from 9,10-dimethyl-ethanoanthracene-2,3,6,7tetraol were reacted with 3,3'-dimethylnaphthidine to form polyimides of intrinsic microporosity, EA-DMN and EAD-DMN, which demonstrated excellent solubility, good thermal stability and 
remarkable microporosity of $\sim 700-800 \mathrm{~m}^{2} \mathrm{~g}^{-1}$. EA-DMN and EAD-DMN films showed promising gas separation properties with performance located between the 2008 and 2015 permeability/selectivity upper bound curves for $\mathrm{O}_{2} / \mathrm{N}_{2}$ and $\mathrm{H}_{2} / \mathrm{N}_{2}$. The gas permeabilities and gas-pair selectivities of the PIM-PIs were strongly dependent on film thickness and age. Based on the results of this study it is suggested that more realistic "intrinsic", that is, quasi-equilibrium gas permeation data can be obtained for mechanically strong, freestanding isotropic membranes with thickness between $\sim 10-30 \mu \mathrm{m}$.

\section{ASSOCIATED CONTENT}

\section{Supporting information}

The Supporting Information is available free of charge via the ACS Publication website at http://pubs.acs.org/.

Gas permeability measurement technique, methanol uptake, gas sorption and diffusion coefficients, long-term aging permeability for EAD-DMN, mechanical properties (PDF).

\section{AUTHOR INFORMATION}

\section{Corresponding author}

E-mail: Ingo.pinnau@kaust.edu.sa

\section{Notes}

The authors declare no competing financial interest.

\section{ACKNOWLEDGMENTS}

This work was supported by funding from King Abdullah University of Science and Technology (KAUST). 


\section{REFERENCES}

(1) Fritsch, D.; Merten, P.; Heinrich, K.; Lazar, M.; Priske, M. High Performance Organic Solvent Nanofiltration Membranes: Development and Thorough Testing of Thin Film Composite Membranes Made of Polymers of Intrinsic Microporosity (PIMs). J. Membr. Sci. 2012, 401-402, 222-231.

(2) Gorgojo, P.; Karan, S.; Wong, H. C.; Jimenez-Solomon, M. F.; Cabral, J. T.; Livingston, A.

G. Ultrathin Polymer Films with Intrinsic Microporosity: Anomalous Solvent Permeation and High Flux Membranes. Adv. Funct. Mater. 2014, 24, 4729-4737.

(3) Wu, X.; Zhang, Q.; Soyekwo, F.; Liu, Q.; Zhu, A. Pervaporation Removal of Volatile Organic Compounds from Aqueous Solutions Using the Highly Permeable PIM-1 Membrane. AIChE J. 2016, 62, 842-851.

(4) Gao, L.; Alberto, M.; Gorgojo, P.; Szekely, G.; Budd, P. M. High-Flux PIM-1/PVDF Thin Film Composite Membranes for 1-Butanol/Water Pervaporation. J. Membr. Sci. 2017, 529, 207214.

(5) Budd, P.; Msayib, K.; Tattershall, C. E.; Ghanem, B.; Reynolds, K.; McKeown, N. B.; Fritsch, D. Gas Separation Membranes from Polymers of Intrinsic Microporosity. J. Membr. Sci. 2005, 251, 263-269.

(6) Carta, M.; Malpass-Evans, R.; Croad, M.; Rogan, Y.; Jansen, J. C.; Bernardo, P.; Bazzarelli, F.; McKeown, N. B. An Efficient Polymer Molecular Sieve for Membrane Gas Separations. Science 2013, 339, 303-307.

(7) Carta, M.; Croad, M.; Malpass-Evans, R.; Jansen, J. C.; Bernardo, P.; Clarizia, G.; Friess, K.; Lanč, M.; McKeown, N. B. Triptycene Induced Enhancement of Membrane Gas Selectivity for Microporous Tröger's Base Polymers. Adv. Mater. 2014, 26, 3526-3531.

(8) Ghanem, B. S.; Swaidan, R.; Ma, X.; Litwiller, E.; Pinnau, I. Energy-Efficient Hydrogen Separation by AB-Type Ladder-Polymer Molecular Sieves. Adv. Mater. 2014, 26, 6696-6700.

(9) Rose, I.; Carta, M.; Malpass-Evans, R.; Ferrari, M.-C.; Bernardo, P.; Clarizia, G.; Jansen, J. C.; McKeown, N. B. Highly Permeable Benzotriptycene-Based Polymer of Intrinsic Microporosity. ACS Macro Lett. 2015, 4, 912-915.

(10) Swaidan, R.; Ghanem, B.; Pinnau, I. Fine-Tuned Intrinsically Ultramicroporous Polymers Redefine the Permeability/Selectivity Upper Bounds of Membrane-Based Air and Hydrogen Separations. ACS Macro Lett. 2015, 4, 947-951. 
(11) Rose, I.; Grazia Bezzu, C.; Carta, M., Comesaña-Gándara, B.; Lasseuguette, E.; Chiara Ferrari, M.; Bernardo, P.; Clarizia, G.; Fuoco, A.; Jansen, J. C.; Hart, K. E.; Liyana-Arachchi, T. P.; Colina, C. M.; McKeown, N. B. Polymer Ultrapermeability from the Inefficient Packing of 2D Chains. Nat. Mater. 2017, 16, 932-938.

(12) Struik, L. C. E. Physical Aging in Plastics and Other Glassy Materials. Polym. Eng. Sci. 1977, 17, 165-172.

(13) Pfromm, P. H.; Koros, W. J. Accelerated Physical Ageing of Thin Glassy Polymer Films: Evidence from Gas Transport Measurements. Polymer 1995, 36, 2379-2387.

(14) McCaig, M. S.; Paul, D. R. Effect of Film Thickness on the Changes in Gas Permeability of a Glassy Polyarylate due to Physical Aging. Part I. Experimental Observations. Polymer 2000, $41,629-637$.

(15) Huang, Y.; Wang, X.; Paul, D. R. Physical Aging of Thin Glassy Polymer Films: Free Volume Interpretation. J. Membr. Sci. 2006, 277, 219-229.

(16) Huang, Y.; Paul, D. R. Effect of Film Thickness on the Gas Permeation Characteristics of Glassy Polymer Membranes. Ind. Eng.Chem. Res. 2007, 46, 2342-2347.

(17) Rowe, B. W.; Freeman, B. D.; Paul, D. R. Physical Aging of Ultrathin Glassy Polymer Films Tracked by Gas Permeability. Polymer 2009, 50, 5565-5575.

(18) Tiwaria, R. R.; Jin, J.; Freeman, B. D.; Paul, D.R. Physical Aging, $\mathrm{CO}_{2}$ Sorption and Plasticization in Thin Films of Polymer with Intrinsic Microporosity (PIM-1). J. Membr. Sci. 2017, 537, 362-371.

(19) Bernardo, P.; Bazzarelli, F.; Tasselli, F.; Clarizia, G.; Mason, C. R.; Maynard-Atem, L.; Budd, P. M.; Lanč, M.; Pilnáček, K.; Vopička, O.; Friess, K.; Fritsch, D.; Yampolskii, Y. P.; Shantarovich, V.; Jansen, J. C. Effect of Physical Aging on the Gas Transport and Sorption in PIM-1 Membranes. Polymer 2017, 113, 283-294.

(20) Swaidan, R.; Ghanem, B.; Litwiller, E.; Pinnau, I. Physical Aging, Plasticization and Their Effects on Gas Permeation in "Rigid" Polymers of Intrinsic Microporosity. Macromolecules 2015, 48, 6553-6561.

(21) Guiver, M. D.; Lee, Y. M. Polymer Rigidity Improves Microporous Membranes, Science 2013, 339, 284-285.

(22) Kim, S.; Lee, Y. M. Rigid and Microporous Polymers for Gas Separation Membranes, Prog. Polym. Sci. 2015, 43, 1-32. 
(23) Robeson, L. M. The Upper Bound Revisited, J. Membr. Sci. 2008, 320, 390-400.

(24) Fritsch, D.; Bengtson, G.; Carta, M.; McKeown, N. B. Synthesis and Gas Permeability Properties of Spirobischromane-Based Polymers of Intrinsic Microporosity. Macromol. Chem. Phys. 2011, 212, 1173-1146.

(25) Rogan, Y.; Malpass-Evans, R.; Carta, M.; Lee, M.; Jansen, J. C.; Bernardo, P.; Clarizia, G.; Tocci, E.; Friess, K.; Lanč, M.; McKeown, N. B. A Highly Permeable Polyimide with Enhanced Selectivity for Membrane Gas Separations. J. Mater. Chem. A. 2014, 2, 4874-4877.

(26) Drechsler, U.; Hanack, M. An Easy Road from Catecols to Phthalonitriles. Synlett. 1998, 1207-1208.

(27) Rabjohns, M. A.; Hodge, P.; Lovell, P. A. Synthesis of Aromatic Polyamides Containing Anthracene Units Via a Precursor Polymer Approach. Polymer 1997, 38, 3395-3407.

(28) Hodge, P.; Power, G. A.; Rabjohns, M. A. Synthesis of Poly(anthracene-2,6-diyl) and a Copolymer Containing Alternately Anthrancene-2,6-diyl and p-Phenylene Units. Chem. Commun. 1997, 73-74.

(29) Liu, C.; Xu, W.; Guan, X.; Yip, H.-L.; Gong, X.; Huang, F.; Cao, Y. Synthesis of Anthracene-Based Donor-Acceptor Copolymers with a Thermally Removable Group for Polymer Solar Cells. Macromolecules 2014, 47, 8585-8593.

(30) Ghanem, B. S.; McKeown, N. B.; Budd, P. M.; Selbie, J. D.; Fritsch, D. High Performance Membranes from Polyimides with Intrinsic Microporosity. Adv. Mater. 2008, 20, 2766-2771.

(31) Rogan, Y.; Starannikova, L.; Ryzhikh, V.; Yampolskii, Y.; Bernardo, P.; Bazzarelli, F.; Jansen, J. C.; McKeown, N. B. Synthesis and Gas Permeation Properties of Novel Spirobisindane-Based Polyimides of Intrinsic Microporosity. Polym. Chem., 2013, 4, 3813-3820. (32) Ma, X.; Ghanem, B.; Salines, O.; Litwiller, E.; Pinnau, I. Synthesis and Effect of Physical Aging on Gas Transport Properties of a Microporous Polyimide Derived from a Novel Spirobifluorene-Based Dianhydride. ACS Macro Lett., 2015, 4, 231-235.

(33) Ghanem, B.; Alghunaimi, F.; Ma, X.; Alaslai, N.; Pinnau, I. Synthesis and Characterization of Novel Triptycene Dianhydrides and Polyimides of Intrinsic Microporosity Based on 3,3'Dimethylnaphthidine. Polymer, 2016, 101, 225-232.

(34) Ma, X.; Abdulhamid, M. A.; Pinnau, I. Design and Synthesis of Polyimides Based on Carbocyclic Pseudo-Tröger's Base-Derived Dianhydrides for Membrane Gas Separation Applications. Macromolecules 2017, 50, 5850-5857. 



\title{
Table of content
}

\section{Effect of Film Thickness and Physical Aging on "Intrinsic" Gas Permeation Properties of Microporous Ethanoanthracene-Based Polyimides}

\author{
Xiaohua Ma and Ingo Pinnau*
}

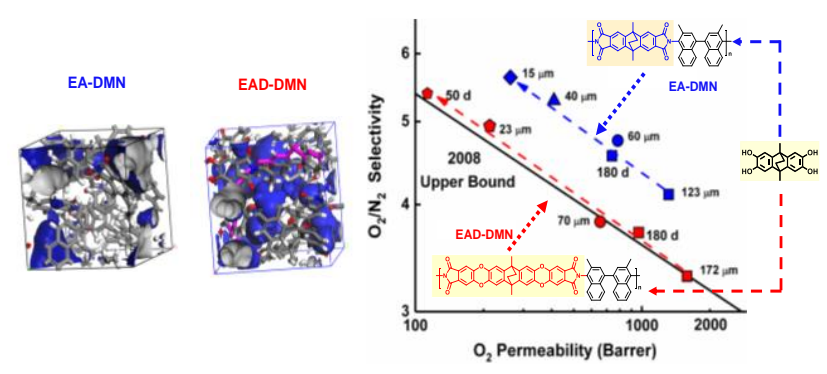

